\title{
Ambiente Colaborativo baseado em Arduino, RFID, QR Code e Visualização de dados para auxílio na identificação de animais perdidos
}

\author{
Maria Vitoria Nunes Lemes \\ Centro de Ciências Tecnológicas \\ Universidade Estadual do Norte do Paraná \\ Bandeirantes/PR, Brasil \\ vitorianunes27@gmail.com \\ Thiago Adriano Coleti \\ Centro de Ciências Tecnológicas \\ Universidade Estadual do Norte do Paraná \\ Bandeirantes/PR, Brasil \\ thiago.coleti@uenp.edu.br
}

\author{
Luiz Fernando Legore do Nascimento \\ Centro de Ciências Tecnológicas \\ Universidade Estadual do Norte do Paraná \\ Bandeirantes/PR, Brasil \\ luizf.nascimento@uenp.edu.br \\ Ricardo Gonçalves Coelho \\ Centro de Ciências Tecnológicas \\ Universidade Estadual do Norte do Paraná \\ Bandeirantes/PR, Brasil \\ rgcoelho@uenp.edu.br
}

\begin{abstract}
Resumo-Há uma grande dificuldade em se localizar um animal doméstico perdido e, muitas vezes, eles não possuem nenhum tipo de identificação. Uma das opções para identificação são os microchips, que são implantados sob a pele do animal. Porém, é preciso que alguém encontre o animal e o leve a um veterinário que possua o leitor de microchip para identificá-lo e por conseguinte encontre seu dono. $O$ objetivo deste trabalho é apresentar um ambiente colaborativo utilizando as tecnologias Arduino, RFID e QR Code para auxiliar o monitoramento e identificação de animais domésticos perdidos. $O$ ambiente desenvolvido permite o ingresso de pessoas para participarem de modo colaborativo. Para a coleta de dados foi desenvolvido um protótipo que permite monitorar as ocorrências de animais em um comedouro, coletando dados por meio de um leitor e uma tag RFID.
\end{abstract}

Keywords-Arduino; RFID; QR Code; Animais Perdidos; Localização.

\section{INTRODUÇÃO}

De acordo com o IBGE, o Brasil tem a segunda maior população mundial de animais domésticos, os quais 52,2 milhões são cães e 22,1 milhões são gatos. Muitos desses animais acabam, em algum momento, se perdendo de seus donos o que pode levar a uma grande dificuldade em encontrá-los.

Existem microchips que podem ser implantados em cachorros e gatos para sua identificação. Os microchips são semelhantes ao código de barras, pois são utilizados para armazenar e transmitir informações. Cada microchip possui um código numérico único que possibilita a identificação do animal [1]. Caso alguém encontre e o leve a um veterinário que possua o leitor de microchips e o acesso a base de dados será possível identificar o animal e visualizar as informações necessárias para encontrar seu dono e, então devolvê-lo.

Entretanto, o Brasil não possui banco de dados unificado para armazenar as informações e não são todas as clínicas veterinárias que dispõem de leitores de microchips [2]. Além disso, a aquisição de microchips para controle dos animais ainda é uma ação com custo relativamente alto, o que restringe a faixa populacional que pode ter acesso ao recurso.

Assim, é apontado como problema desta pequisa a falta de uma base de dados unificada, uma rede mais ampla de monitoramento, um equipamento com baixo custo e uma forma acessível de aquisição/uso para um grupo mais amplo de proprietários de animais domésticos.

Considerando esta necessidade, este trabalho propõe uma abordagem baseada em uma plataforma livre e um ambiente colaborativo com o objetivo de auxiliar no monitoramento, localização e identificação de animais domésticos. Para a construção do ambiente pretende-se utilizar as tecnologias RFID, QR Code e a plataforma de prototipagem Arduino.

Para o monitoramento em geral, acredita-se que a abordagem possa facilitar o ingresso de pessoas e empresas como pontos de monitoramento e identificação, uma vez que estações de monitoramento poderão ser instalados e configurados com custo reduzido e de forma simples.

No que tange o proprietário dos animais domésticos, acredita-se na facilidade na obtenção dos dispositivos para monitorar os animais e em uma base de dados que possa abranger uma área maior de monitoramento.

\section{REVISÃo BIBLIOGRÁFICA}

Está seção apresenta a revisão bibliográfica dos principais componentes que suportam a proposta do ambiente colaborativo para monitoramento e identificação de animais domésticos.

\section{A. Arduino}

O Arduino é uma plataforma eletrônica open-source que pode ser conectado a diversos sensores e atuadores. Esses 
componentes permitem a construção de sistemas que percebem a realidade e respondem com ações físicas desejadas tais como abrir portas, acender e apagar uma lâmpada, dentre outras possibilidades. Foi projetado baseado em um microcontrolador Atmel, possui acessos de Entrada/Saída (I/O), trabalha com bibliotecas desenvolvidas com funções para simplificar sua programação e utiliza uma linguagem de programação baseada em $\mathrm{C} / \mathrm{C}++$ [3].

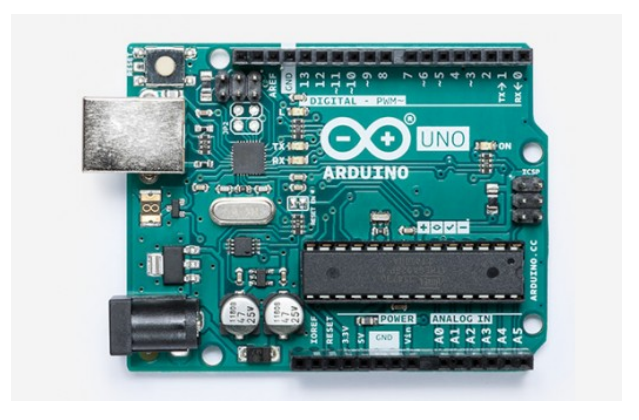

Figura 1. Arduino Uno [4].

A plataforma Arduino possui hardware e software livre, permitindo que seu código fonte e hardware possam ser alterados por qualquer pessoa para a criação de aplicações em diversas áreas.

\section{B. Leitor RFID MFRC522}

O Arduino, possui um módulo leitor de RFID, apresentado na Figura 2, que pode ser utilizado em comunicações com frequência de 13,56 MHz. Este módulo utiliza o chip MFRC522 da empresa NXP, que permite sem contato ler e escrever em cartões que seguem o padrão Mifare, muito utilizado em projetos de controle de acesso.

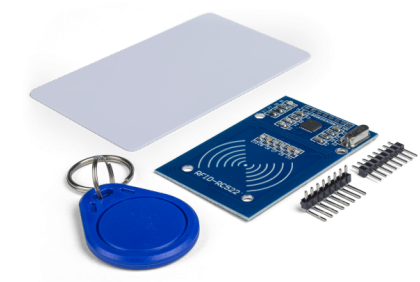

Figura 2. Leitor RFID MFRC522 [4].

Além de cartões, o módulo leitor possui as tags (ou etiquetas) RFID, que podem conter vários dados sobre o proprietário ou sobre produtos. Há também as tags em formato de chaveiro [5].

\section{C. $Q R$ Code}

O QR Code pode ser utilizado para a visualização de informações de forma rápida e prática, e para isso pode ser aplicado de diversas formas. Inicialmente era utilizado na área automotiva para a catalogação de peças de carros a fim de facilitar e agilizar processos de produção e manutenção. É comparado por muitas pessoas ao código de barras tradicional, mas entre eles há diferenças como: representação gráfica e volume de informações que podem ser representados.

Essa tecnologia é uma opção para armazenar várias informações ao contrário do código de barras que normalmente armazena uma lista de caracteres numéricos. O QR Code pode ter seu conteúdo convertido em um texto, hyperlink, um e-mail em uma informação geo-referenciada dentre outros.

A decodificação (leitura) desses dados, é feita por intermédio de um smartphone com o aplicativo que faz a leitura através da câmera, os dados capturados são convertidos em informações. Qualquer pessoa pode fazer uso dessa tecnologia, para isso basta acessar um site gerador de QR Code e escolher o que se encaixa melhor com sua necessidade [6].

Os leitores para QR Code são facilmente encontrados em forma de aplicativos para smartphones que podem ser adquiridos gratuitamente. Este cenário facilita a utilização, pois não requer nenhum tipo de equipamento especial para acessar a informação.

O QR Code passou a ser muito utilizado em ações como marketing, vendas, identificação de mercadorias, notas fiscais eletrônicas, Internet das Coisas (IoT) e outras ações que buscam disponibilizar um conjunto maior de informações com um meio visual compacto [7].

\section{Ambiente De Monitoramento Colaborativo}

Esta seção apresenta a proposta do ambiente de monitoramento colaborativo e suas funcionalidades.

\section{A. Aspecto Colaborativo do Ambiente}

$\mathrm{O}$ conceito de monitoramento colaborativo refere-se à ideia de criação de uma rede de sensores sem fio envolvendo os dispositivos carregados por participantes durando o diaa-dia, com o intuito de se estabelecer uma infraestrutura de coleta de dados colaborativa [8].

Diante dessas considerações o ambiente proposto neste trabalho pretende facilitar o ingresso de pessoas para que possam participar de maneira colaborativa com o ambiente, tendo o objetivo de facilitar o monitoramento, a localização e a identificação de animais domésticos perdidos, a Figura 3 apresenta o modelo conceitual do ambiente.

Para o ingresso de pessoas propõe-se três formas: (1) Através da aquisição de um comedouro de monitoramento; (2) Por meio da aquisição de uma tag RFID para ser colocada na coleira do animal; e (3) por meio da tecnologia QR Code. 


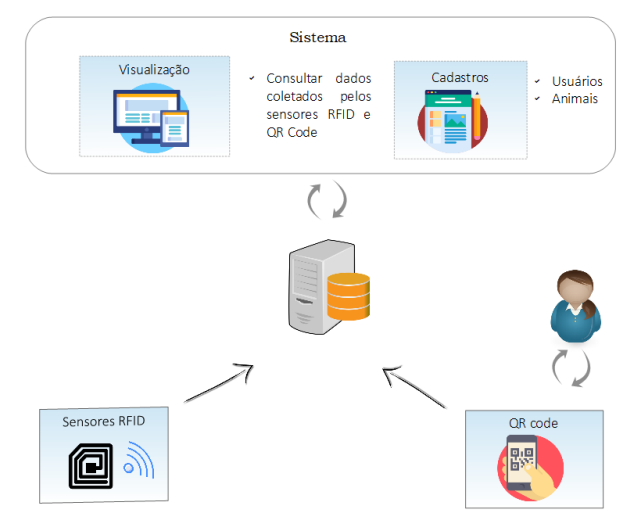

Figura 3. Modelo conceitual do ambiente colaborativo.

Propõe-se também que o usuário possa adquirir um comedouro e posicioná-lo onde preferir, para que o mesmo monitore as ocorrências de animais que se aproximarem. Para a visualização dos dados pretende-se utilizar técnicas que permitam o Georreferenciamento com suporte de mapas e pontos plotados nas posições as quais os animais foram identificados. Cada ponto apresentará um conjunto de dados que deverá auxiliar o proprietário/veterinário na identificação.

Para a identificação por meio de sensores é preciso ter uma tag RFID no animal. Nesse projeto a tag utilizada foi a do tipo passiva, em formato de chaveiro, pelo fato de poder ser colocada em uma coleira e facilitar o processo de identificação por meio do comedouro de monitoramento.

Para colaborar por meio da tecnologia QR Code o usuário precisará cadastrar seu animal no site da aplicação, para isso pretende-se fornecer um código $\mathrm{QR}$ ao usuário contendo essas informações para que seja impresso e colocado em uma coleira ou outro objeto, desde esteja no animal a ser identificado. Qualquer pessoa que possuir um smartphone com o leitor de QR Code poderá fazer a leitura do mesmo e visualizar as informações do animal caso ele se perca.

\section{B. Aspecto Técnico do Ambiente}

O ambiente proposto terá dois meios de coleta de dados: (1) Por meio de sensores RFID; (2) Tecnologia QR Code. A coleta de dados pelo comedouro é feita com base no uso de um sensor RFID conectado ao Arduino, por meio deste protótipo é possível fazer a leitura da tag RFID presa à coleira do animal. Para que isso aconteça, o animal precisa se aproximar do comedouro. Um dos motivos para a escolha do comedouro foi pelo fato de que o mesmo possa atrair a atenção do animal, para que ele se aproxime perto o suficiente do leitor RFID.

Já a coleta de dados por QR Code seria feita por meio da leitura do código QR impresso na coleira do animal. $\mathrm{O}$ código irá conter as informações do animal e de seu dono, ao ler o QR Code da coleira o voluntário poderá enviar os dados do animal, juntamente com os dados de localização para a base de dados da aplicação ou enviá-las diretamente para o dono do animal.

Os dados coletados serão enviados para uma base de dados e poderão ser visualizados por uma página HTML. Por essa página serão realizados os cadastros de usuários, para que os mesmos possam ter acesso aos recursos da página, cadastros de animais e cadastros de comedouros, esses dados serão armazenados na base de dados para serem trabalhados pela aplicação posteriormente.

\section{Comunicação entre Componentes}

O Arduino juntamente com o módulo leitor RFID precisa gravar os dados coletados em um banco de dados, para que isso fosse possível foi desenvolvido um programa na linguagem Java. O microcontrolador utiliza comunicação serial para envido dos dados, o programa foi elaborado estabelecendo a leitura dos dados recebidos pela porta serial. Para isso, utilizou-se a biblioteca RXTX que permite a comunicação serial do computador com o Arduino, na linguagem de programação Java. Esse programa serviu como uma ponte para a comunicação entre o Arduino e o banco de dados, recebendo os dados captados pelo sensor RFID e os enviando ao banco de dados.

Posteriormente a aplicação web recupera os dados coletados pelos sensores para que o usuário possa visualizá-los. $\mathrm{O}$ protocolo utilizado para a comunicação WEB foi o HTTP.

\section{Acesso as informações pelos usuários}

Para o desenvolvimento do site da aplicação utilizou-se principalmente a linguagem PHP, para a manipulação da base de dados, HTML para a visualização das informações e um framework Bootstrap. No desenvolvimento da parte de cadastro e login do usuário utilizou-se a função hash SHA256, com 64 bytes de comprimento para a criptografia das senhas. Ao se cadastrar e fazer o login, o usuário terá acesso às ferramentas da aplicação.

Para demonstrar o funcionamento da aplicação, a seguir são apresentadas as telas e as ferramentas presentes no site, juntamente com suas descrições. A Figura 4 apresenta a interface inicial do site, o usuário será direcionado à esta tela após fazer seu cadastro e login. 


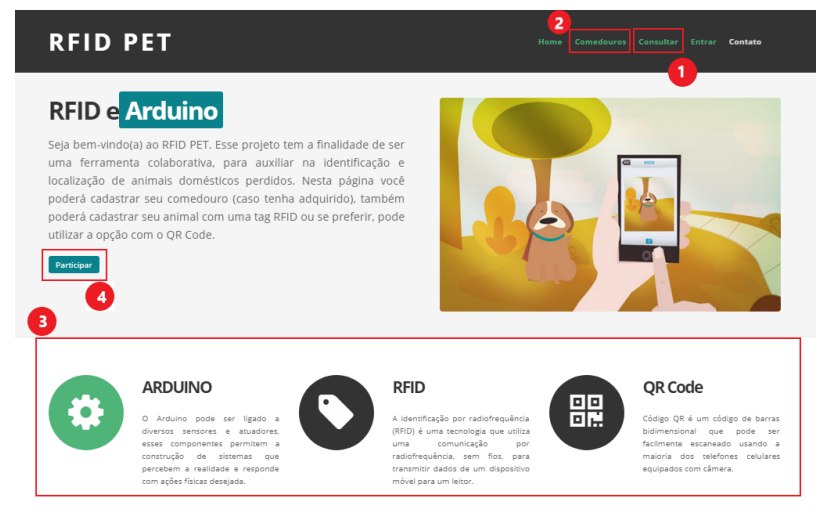

Figura 4. Página inicial

A consulta (1) irá apresentar ao usuário uma tabela com os dados de ocorrências de animais, contendo o número do comedouro, bem como os dados de identificação de cada animal, Figura 5. No mapa estará plotado a localização dos comedouros cadastrados que podem ser visualizados na aba Comedouros (2), como será mostrado na próxima seção, na Figura 7.

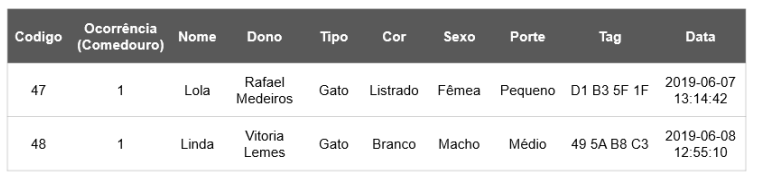

Figura 5. Visualização de ocorrências de animais.

A página inicial também apresenta algumas informações sobre os principais componentes utilizados para o desenvolvimento do projeto (3), destacando as características do Arduino, RFID e QR Code.

Ao clicar em Participar (4), o usuário terá acesso a tela de opções do ambiente colaborativo. A tela irá apresentar três opções ao usuário, na primeira opção o usuário poderá cadastrar um animal, inserindo as seguintes informações: nome do animal, nome do dono, tipo (cachorro ou gato), cor, sexo, porte e código da tag RFID.

As informações cadastradas identificam o animal posteriormente, como foi apresentado na seção anterior, na Figura 5. Já na segunda opção o usuário entra como um colaborador ao adquirir e cadastrar um comedouro. Para cadastrar o comedouro o usuário adiciona as informações geográficas (latitude e longitude) de onde ficará posicionado seu comedouro. Ao fazer isso a aplicação passa a exibir o comedouro com um marker no mapa e suas informações.

Utilizando o mapa como base, o usuário pode visualizar em uma tabela as ocorrências de animais e o comedouro em que o animal esteve, como foi dito anteriormente. Para a implementação do mapa na página e a definição de cada ponto de marcação foi utilizada a API JavaScript do Google Maps.
A terceira opção, ajudará na identificação e localização do animal através da tecnologia QR Code. Essa tecnologia é constituída de uma série de códigos e caracteres decodificados em uma imagem quadrada, dispondo de uma alta capacidade para armazenar dados.

Utilizando essa tecnologia, propõe-se que código QR será impresso na coleira do animal, o código irá conter as informações do animal e de seu dono, ao ler o QR Code da coleira o voluntário poderá enviar os dados juntamente com os dados de localização para a base de dados da aplicação ou enviá-las diretamente para o dono do animal.

\section{VALIDAÇÃO}

Esta seção apresenta a validação da proposta, sendo validado: o cadastro de animais e comedouros, a aplicação do comedouro e a visualização dos dados.

\section{A. Protótipo do comedouro}

O protótipo do comedouro, apresentado na Figura 6, foi desenvolvido utilizando uma placa Arduino Uno R3 e um Módulo RFID MFRC522 de 13,56 Mhz. O comedouro utilizado para a construção possui um fundo com um espaço para acoplar o Arduino juntamente com o leitor RFID. Para enviar os dados necessários para o leitor, foi utilizada uma tag RFID no formado de chaveiro, com o intuito de ser presa à uma coleira. A partir do momento que se aproxima a tag do leitor, os dados pré-cadastrados com o código identificador da $\operatorname{tag}$ são gravados na base de dados.

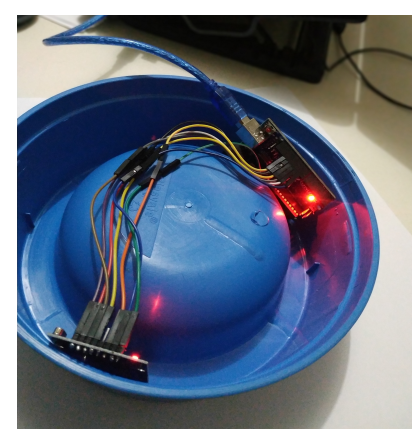

Figura 6. Protótipo do comedouro

Cada tag contém um código identificador, esse código servirá para identificar o animal posteriormente juntamente com seus dados, sendo: nome, dono, tipo, cor do animal, sexo e porte. Os dados podem ser cadastrados através da aplicação Web.

Para o desenvolvimento do algoritmo do comedouro foi utilizada a linguagem Java, o algoritmo faz a leitura da tag RFID e grava os dados no Banco de Dados. Para a inserção dos dados no banco, utiliza-se o código identificador da tag como elemento principal, já que é esse código que irá identificar o animal posteriormente.

No processo de cadastro de um animal, o usuário cadastra as informações do animal que deseja identificar, juntamente 
com o código de uma tag RFID, para ser colocada posteriormente em uma coleira.

Ao adquirir um comedouro o usuário faz o cadastro de suas informações no site, onde irá informar os dados de localização (latitude e longitude) do local em que o comedouro ficará posicionado. Para a aplicação do protótipo do comedouro em um ambiente real foi cadastrada sua posição geográfica no sistema.

O usuário também pode visualizar a localização dos comedouros já cadastrados, como mostrado na Figura 7. Selecionando o marker é possível ver o endereço em que o comedouro está posicionado.

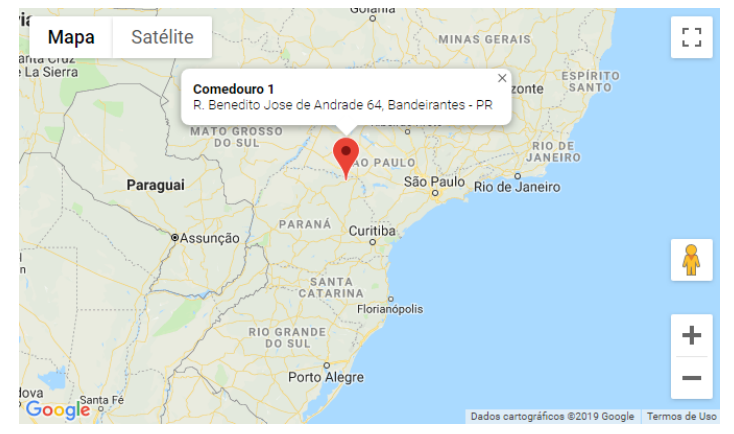

Figura 7. Localização dos comedouros

Para a validação do comedouro, foi realizado um teste aplicado em ambiente real. Foi simulado o cadastro de dois gatos, juntamente com o código da tag RFID (em formato de chaveiro), que foi colocada em uma coleira. Inicialmente os gatos se incomodaram um pouco com a coleira, pode ser pelo fato de nunca terem usado uma. Para atrair a atenção dos animais, foi colocado um pouco de ração no comedouro e deixado em um local para que eles se aproximassem por conta própria. O primeiro gato se aproximou por curiosidade e ficou para comer a ração, como ele se aproximou o suficiente do leitor foi possível fazer a coleta dos dados e armazená-los na base de dados. O segundo teste foi realizado no dia seguinte, com o outro gato. O comedouro foi deixado em um canto da casa para que o gato se aproximasse quando tivesse fome. Depois de um tempo em que o comedouro estava posicionado, o gato se aproximou para comer e então o leitor coletou os dados da tag RFID presa a sua coleira.

Com a aplicação foi possível visualizar a hora e data exata em que o animal se aproximou do comedouro. Além da data e a hora da ocorrência, o sistema também apresenta as informações do animal, que foram cadastradas anteriormente, referenciadas por sua tag RFID, como foi apresentado na Figura 5.

\section{CONClusão}

Este trabalho apresentou um estudo elaborado para o desenvolvimento de um ambiente colaborativo, com o objetivo de auxiliar na identificação e localização de animais domésticos perdidos. Para isso apresentou o desenvolvimento de um protótipo como ferramenta de coleta de dados e também uma proposta para aplicar o protótipo juntamente com a tecnologia QR Code.

$\mathrm{O}$ ambiente desenvolvido atendeu aos objetivos esperados. O protótipo possibilita o monitoramento de ocorrências de animais no comedouro e com o mesmo é possível coletar os dados do animal utilizando a tag RFID e visualizá-las posteriormente em uma página HTML.

Nos testes realizados com o comedouro foi possível coletar os dados da coleira do animal sem muitas dificuldades, pois o mesmo foi posicionado com o leitor para frente, se posicionado de outra maneira pode ser que tivéssemos mais problemas para coletar os dados, o animal também pode se aproximar pelo lado do comedouro e não pela frente.

Para resolver este tipo de problema, pode-se utilizar uma tag RFID do tipo ativa, juntamente com um leitor correspondente, que possuem um alcance de leitura maior e permitem a realização de tarefas mais complexas, porém o custo para adquirir esses componentes são elevados.

Quando um animal doméstico se perde, pode haver uma certa dificuldade em encontrá-lo, principalmente se não possui nenhum meio para identificação. $\mathrm{O}$ ambiente desenvolvido poderá ajudar donos de pets e veterinários a identificar e localizar o animal caso ele se perca, mas para que isso aconteça é necessário a colaboração de mais pessoas, por meio dos comedouros e do QR Code. Essa última forma de auxiliar a localizar o animal pode ser utilizada por qualquer pessoa, deste que ela tenha um smartphone com o aplicativo leitor de código QR.

\section{REFERÊNCIAS}

[1] L. Matieli and S. Curto, "Microchip - A Identificação Eletrônica dos Animais," 2009. Artigo (Trabalho Específico para a disciplina Administração de Sistema de Informação) - Centro Universitário do Espírito Santo - UNESC. Colatina (ES).

[2] Canal do Pet, "Sane todas as suas dúvidas sobre microchip para cães e gatos," 2018.

[3] B. F. d. B. Santos, "Alimentador Automático para Animais Utilizando Arduino," 2015. 51 f. Trabalho de conclusão de curso (Bacharelado - Engenharia Elétrica) - Universidade Estadual Paulista, Faculdade de Engenharia de Guaratinguetá, 2015.

[4] "What is arduino," 2018.

[5] A. L. Stefanello, Utilização de rfid na identificação de pessoas. Especialização em gestão da tecnologia da informação, Universidade Federal de Santa Maria, Frederico Westphalen, RS, 2013.

[6] A. R. R. de FREITAS, QR CODE - TENDÊNCIA DE EVOLUÇÃO COMERCIAL NO PONTO-DE-VENDA FISÍCO. Dissertação, Universidade Europeia, 2017. 
[7] A. C. Ribas, B. S. Oliveira, C. A. Gubaua, G. d. R. Reis, and H. S. H. Contreras, "O Uso do Aplicativo Qr Code como Recurso Pedagógico no Processo de Ensino e Aprendizagem," Ensaios Pedagógicos, vol. 7, no. 2, pp. 12-21, 2017.

[8] D. S. Gallo, Monitoramento colaborativo para cidades inteligentes. Tese (doutorado), Escola Politécnica da Universidade de São Paulo, São Paulo, 2016. 